\title{
Health Needs of the Nation
}

\author{
SURGEON GENERAL LUTHER L. TERRY
}

$\mathrm{N}^{\wedge}$ ATIONAL HEALTH is nothing more nor less than the health of every State, every community, and every individual. All of us share the responsibility for solving three major health problems.

The first is the changing pattern of disease in our growing population. The past two decades have witnessed the virtual conquest of bacterial diseases. In that period, chronic diseases have continually risen in prominence as causes of death and even more so as causes of prolonged disability. This problem is closely associated with the medical needs of the aged, since cardiovascular disease, cancer, and metabolic diseases strike most severely in the later years of life. But chronic conditions also inflict the highest disability rates in all age groups, from early infancy through the most productive years of adulthood.

The second problem is a corollary of the first; namely, the provision of comprehensive health care for 180 million people. The core of this problem is our lack of facilities and personnel and of effective organizations for the application of medical science to human needs. We need more efficient systems of financing medical care for aged and dependent groups. Modern medicine has a vast array of preventive, curative, and restorative techniques, and if these were readily available to all segments of the population in all communities, we could anticipate a substantial reduction in costly long-term disability.

The third problem is the emergence of new environmental threats to life and health. These

Dr. Terry, Surgeon General of the Public Health Service, delivered the address on which this paper is based before the joint session of the Alabama Legislature, Montgomery, Ala., July 18, 1961. include ionizing radiations, chemical wastes in the atmosphere and water resources, and the use of new chemicals in foods and domestic products. Both rural and urban populations are confronted with increased exposures to these hazards.

Our hopes for ultimate success in solving these major problems depend upon one common factor: continued progress in the health sciences. During the past 15 years, our national health policy has given highest priority to the expansion of medical research. The result has been greater advances in scientific medicine than in any prior period.

We can anticipate further medical advances under that policy. But many problems in the life sciences remain unsolved; many research areas affecting human health are little explored. Notable among these areas are the environmental sciences, the behavioral sciences, and administrative research. Also of critical concern is the fact that the health professions in many parts of our country lack the essential support of strong research programs.

\section{Chronic Illness and the Aged}

In considering chronic illness, we need to bear in mind the great population changes that are taking place. The nation's population totaled 180 million in 1960, an increase of 18.5 percent over 1950. The two groups with the highest rates of growth were the children and the aged. The child population under 18 years of age increased 37.6 percent and the aged over 65 years increased nearly 35 percent. These trends will continue for the next few decades, with a predicted total population of 214 million in 1970.

In States like Alabama, where population growth is slow, the proportional increase of the 
aged population may be much higher. For the nation as a whole, the aged increased at a rate almost twice that of the total population in the past decade. Alabama's aged population increased by 31.5 percent, a rate more than four times that of the State population as a whole (6.7 percent).

There are ample data to document the special health problems of the aged. At least 77 percent of persons 65 years of age and over have one or more chronic ailments. These conditions do not always disable, but more than 6 million older people who are not in institutions report some limitation of their usual activities as a result of chronic conditions. About 2 million in that group are invalids in the commonly accepted sense of the term, that is, they are in chronic ill health and disabled for active life.

Approximately half a million older people are in nursing homes and similar institutions and another quarter of a million or more are in mental hospitals. From past experience, we know that in most of these institutions, the elderly patients are very old and very sick, and are receiving inferior service and very little medical care.

The high prevalence of chronic illness in the aged has stimulated national concern to find a satisfactory system for financing their medical expenses. President Kennedy has proposed the extension of our social security system to provide health insurance for aged beneficiaries. In my opinion, that is the logical, the most satisfactory approach. Our experience with other approaches indicates that for the majority of old people, the action is too little and too late. Whatever the nation's decision is in this matter, there can be no doubt in anyone's mind that we must be prepared to provide more and better medical services for increasing numbers of older people.

The chronic diseases, which cause the largest volume of prolonged disability, may have their onset at any time of life. There are about 70 million persons in the United States with one or more chronic conditions. Less than half of these $(32,147,000)$ are 45 years of age and over. In these groups, however, the rate of chronic illness as well as its severity increases sharply with age. Among persons 45-64 years old, 56 percent have chronic ailments, and that rate in- creases to 83 percent at age 75 and older. The percentage of persons with partial or major limitations due to chronic illness increases progressively from 13 percent in the younger group (45-64) to 55 percent in the older.

The health professions have long recognized that the best hope for coping with chronic disease is a preventive approach. In 1947, the American Hospital Association, the American Medical Association, the American Public Health Association, and the American Public Welfare Association issued this joint statement:

"The basic approach to chronic disease must be preventive. Otherwise the problems created by chronic diseases will grow larger with time, and the hope of any substantial decline in their incidence and severity will be postponed for many years."

The earlier a chronic disease is diagnosed, the better the prognosis. If appropriate treatment is instituted promptly and medical supervision is maintained, the patient may live a long, active life with relatively little residual disability. This has been my experience as a clinician in the management of many cardiovascular patients.

It is true that a vast amount of basic and clinical research must be done before we have "sure cures" or simple preventive measures for most of the chronic diseases. In fact, as medical science advances, the more complex the causation of disease appears. But medicine has accumulated a battery of remarkably effective preventive weapons against chronic conditions in the past 15 years. The prophylactic use of antibiotics, for example, has sharply reduced the incidence and mortality of rheumatic heart disease and subacute bacterial endocarditis. Anticoagulants have given a new lease on life to patients who survive their first coronary attack. The use of steroid compounds to suppress rheumatoid inflammation has prevented severe crippling in many arthritic patients. Exchange transfusions for $\mathrm{Rh}$ negative infants have virtually eliminated one form of cerebral palsy.

In addition, advances in diagnostic techniques have greatly increased efficiency in discovering serious chronic disease at a time when the chances of cure are best. Among these are improvements in the electrocardiograph and the electroencephalograph, the use of the tonom- 
eter to detect glaucoma, and the cytological test for cancer of the uterus.

In sum, the "prognosis" for a national attack on chronic disease is far better than it ever has been in the past. We need to continue and to expand our research effort. This we will do, but we must begin now to apply throughout the country all the gains we have made in scientific knowledge and medical skill.

\section{Comprehensive Health Care}

The second major health problem that confronts this nation is the provision of comprehensive health care.

In his first health message, President Kennedy recognized the importance of this national problem, and he has emphasized it in subsequent special messages. In his recommendations for community health facilities and services, the President stated that the ability of families and individuals to purchase health care is of no avail if their communities do not have the necessary facilities and services.

The concept of comprehensive health care has emerged within the past decade as scientific progress has taught the health professions that there can be no separation of their basic responsibilities : prevention, care, and restoration.

In the distant past, it was possible to separate our very few preventive measures from the treatment of acutely ill people. Later on, a few surgeons seized the opportunities offered by their care of severely wounded soldiers to develop rehabilitative, or restorative, medicine. After the war, rehabilitative services were extended to the industrially injured and subsequently to a larger group of handicapped persons in our national programs for crippled children and vocational rehabilitation.

The goal now is to make sure that preventive, curative, and restorative services are available to all persons who need them, at the times they are needed, and wherever they are needed.

The core of the comprehensive medical care problem is facilities and personnel, and it is inextricably linked with the costs of health services. Medical care prices have risen more than 40 percent in the past decade, twice the percentage increase in the average price of all consumer goods and services for the same period. There is no indication that this rising trend in prices will halt, and there has been no corresponding increase in the income of the aged in the same decade. Moreover, private carriers of health insurance, with few exceptions, have not offered to the aged the same coverage and benefits that they offer to younger groups.

Improvement of community health facilities and services will not reduce the nation's annual medical bill of $\$ 25$ billion. In fact, if all our medical knowledge were applied wherever and whenever it is needed, that bill for a growing population would be substantially higher. The American people, however, want the best that medicine can provide. They have financed the scientific research that makes advancement possible. They will, I feel sure, find ways to pay the price of better medical care.

As a nation, we have made substantial progress under the Hill-Burton program in reducing the deficit of general hospital beds, particularly in rural areas. In 1948, when construction began under the program, we had only 59 percent of the needed general hospital beds. By 1960 , the States reported that 80 percent of the national need had been met.

A growing and mobile population has sharply increased the need for general hospitals in suburban areas, however. Also, many of our oldest and most famous hospitals in central cities urgently need new facilities. Of special importance is the development of adequate teaching, research, and service facilities for the nation's medical centers.

The most serious deficits in service facilities are in nursing homes, in new types of facilities for the intensive treatment of mental patients, and in rehabilitation facilities. As of January 1,1960 , the national deficit in nursing home and chronic disease beds was reported to be more than 500,000. Both types of facilities provide long-term care, chiefly for the aged. Legislation now before the Congress would authorize an additional $\$ 10$ million in Hill-Burton grants for the construction of nursing homes. If this increase is provided, the combined funds for chronic disease hospitals and nursing homes would total $\$ 40$ million a year in grants. If States and communities utilize these grants, it will be possible to add about 10,000 nonprofit beds for long-term care each year. It can be expected that commercial nursing home facilities 
will continue to increase, and probably at a faster rate under expanded Federal-State programs for medical care of the aged.

The nation's needs for teaching and research facilities in the health field are intimately associated with our shortages of professional personnel.

The shortage of physicians and dentists has been an ever-increasing problem for the past two decades. The national ratio of physicians to population has remained about the same, 132 per 100,000, in a period of great and rapid population growth. Many parts of the country are not as well off as they were in 1940.

We need to strengthen and expand our existing schools; and we need to build new ones. We need to recruit our best young men and women for careers in the health professions.

President Kennedy's recommendations for educational assistance for health professions would authorize a 10-year program of matching construction grants for medical, dental, and public health schools, at a rate of $\$ 60$ million a year. New schools or major expansions of existing schools would receive up to 60 percent of costs in Federal grants, while the ratio for renovation would be 50-50. The proposal would also extend the Public Health Service construction grant program for research facilities for 3 years and increase the authorization to $\$ 50$ million a year. The recommendations would make available scholarship grants to medical and dental schools for aid to students requiring financial assistance. The schools would also receive instructional grants equivalent to $\$ 1,000$ per Federal scholarship holder.

These proposals have had wide approval from the professions and the public. They would make a start toward meeting the longstanding deficits in professional health personnel.

Many States with severe economic problems have made heroic efforts since World War II to strengthen their educational and health programs. These problems are complex, they are difficult to solve, and their solution is costly. I believe, however, that State governments face a broader responsibility in relation to health than ever before. Federal aid in various fields, notably medical research, hospital construction, and public health programs, has been substantial over the past decade. I believe that it will increase and extend into new areas, but the Federal Government cannot carry the entire burden of public responsibility for growing health needs.

I believe that in the next decade the increase in service occupations will be a tremendous source of economic development. Automation in industry will create many new jobs requiring higher levels of education and training. So also in health services, advances in science and technology will create new opportunities demanding special skills. The kinds of specialists and technicians employed in comprehensive health services already have increased. Today there are four professional health workers for every physician. These additional workers provide the nursing care, the laboratory and pharmacy services, and many of the special treatments, such as physical therapy, which the physician requires in the management of his patients. $\mathrm{He}$ is responsible for making the diagnosis and prescribing the treatment, but an army of professional and technical personnel carry out his instructions.

Most of these services are available in the modern hospital. But if we are to provide comprehensive health care for 180 million people we must find ways to bring more of these services to the people - in their own homes, in nursing homes, and in facilities for ambulatory care. It is wasteful of professional personnel and funds to keep patients in hospitals beyond the time when the full battery of specialized hospital equipment and service is needed.

Organized community services to provide comprehensive health care outside the hospital are available in only a few parts of the country. Yet where even partial programs are in operation, their values in improving the health of the people and reducing the costs of care have been demonstrated.

For example, simple exercises and other therapeutic measures can have patients who survive stroke walking within 2 months of the attack. The longer the period before these measures are instituted, the longer the patient is flat on his back, and the harder it is to restore function. But even severely paralyzed patients, after lying in bed for years, have recovered enough function to take care of their daily personal needs. 
This particular method of carrying out the restorative phase of comprehensive health care is probably the least expensive technique in the entire medical armamentarium. Properly instructed, any intelligent adult can do what is needed for the stroke patient; and the patient is soon exercising himself.

If this is known, why are so many victims of stroke "permanently and totally disabled"? The basic reasons are related to education of the health professions, traditional ideas of what severely ill patients can and cannot do, and the tendency in nursing homes to keep patients in bed and docile. But health departments all over the country are jumping at the chance to put rehabilitative measures into operation. For example, the Georgia Department of Public Health and the Emory University School of Medicine have teamed up, with help from the Public Health Service, for this purpose. They are providing community services to institute restorative techniques in nursing homes and the homes of stroke patients.

President Kennedy's proposal for strengthening community health facilities and services would increase Public Health Service grants to the States for these purposes. It would expand efforts to improve the quality of care in nursing homes, as well as programs for chronic disease control. It would encourage the development of comprehensive health care programs in local communities. And it would provide support for special projects in public and private organizations designed to develop new and better methods of delivering comprehensive services.

\section{Environmental Health}

The third major health problem, new environmental hazards, has been advancing upon us for 20 years. The principal areas of concern are water and air pollution, the use of new chemicals, and ionizing radiation. Within these broad fields there are the specialized problems of industrial workers exposed to new processes and the concentration of environmental problems in metropolitan areas.

In the main, these problems are byproducts of technological progress. They are accompanied and exacerbated by population growth and increased urbanization. As a result, the
American people are confronted with a dilemma: How can we create a healthful environment, conserve our natural resources, and at the same time retain the benefits of industrial technology? These benefits have added immeasurably to the convenience and, in many ways, to the healthfulness of daily living. But they have also imposed heavy hidden burdens on human health and on the economy.

Water pollution has driven up the costs of industrial production and of municipal water supplies. It has seriously depleted the nation's fish and wildlife and its recreational areas. It has had adverse effects on animal industry and agriculture. And it is a very real and present danger to human beings.

Last February, there was an outbreak of infectious hepatitis in Pascagoula, Miss., which eventually totaled 80 cases in Pascagoula and Jackson County, Miss., and in Troy and Mobile, Ala. Epidemiologic studies by the Public Health Service traced the source to raw sewage discharged into the Pascagoula River, which eventually infected oysters which the victims had eaten. The shellfish were harvested from presumably safe reefs in the coastal area.

In investigating this puzzling outbreak and halting its spread, the health departments of Mississippi and Alabama and the Mississippi Marine Conservation Commission cooperated with the Public Health Service. Later this year water pollution was the source of another outbreak of infectious hepatitis in New Jersey and New York. This outbreak was traced to clams taken from Raritan Bay. These two disease outbreaks emphasize that water pollution knows no political boundaries, and that it affects both fresh and salt water resources, long distances from the point of waste discharge.

Air pollution from industrial and domestic sources and automotive traffic is a recognized problem in all metropolitan areas, and a serious one in many. The production and use of chemicals and ionizing radiation have added enormous dimensions to the environmental problem. It is further complicated by the lack of uniform laws and regulations in this great national complex of State and local jurisdictions.

What can we do about it? The first need is for a greatly expanded national research, train- 
ing, and development effort in the environmental sciences, comparable with our efforts in medical science, aeronautics, and space research. Lack of scientific knowledge and efficient control equipment is the chief handicap which deters governmental agencies at all levels in their efforts to protect natural resources and human health. So far as health is concerned, the great unknown is the biological effects of small, intermittent doses of radiation and new chemicals over long periods of time.

A second major need in environmental health is for funds and a coordinating mechanism to bring together specialists in a wide variety of fields at national, State, and municipal levels. The objective would be to apply interdisciplinary analysis, planning, and logistics to specific problems, as well as to the total environment of different regions or metropolitan areas.

The Public Health Service has had responsibilities, including some regulatory duties, in environmental fields since early in this century. It acquired additional responsibilities, particularly in water and air pollution control and radiological health, during the 1950's.

One of our goals now is to speed water pollution control, especially through increased research, training, and financial grants to municipalities for the construction of waste treatment facilities.

We expect also to expand research, training, and technical assistance in all environmental fields. President Kennedy has requested funds for the site acquisition, planning, and design of a National Environmental Research Center. Various field centers, some of which are already in being, will be developed to conduct field investigations and provide technical assistance to adjacent regions.

\section{Role of Governments}

The problems and programs I have mentioned represent only a sample of the nation's health needs and resources. In all these areas and in others, public and private resources have poured into the breach to meet urgent needs. If this were not so, American medicine and public health would not have attained their present high levels of proficiency. Without public and private action, we would not have our universities, hospitals, health departments, voluntary agencies, and pharmaceutical and instrumentation industries.

In certain areas, joint planning and action by public and private organizations has brought about sustained progress over the past two decades. Usually, the beginnings have been small; but in some instances the results have been spectacular. Two notable examples are the national medical research effort and the national hospital and medical facilities program. Both have gone from strength to strength largely as a result of the active cooperation of professions, governments, industries, nonprofit institutions, and voluntary associations. This great complex of private and public resources is now called upon for similar efforts in different, but closely related, areas. Concerted action has made possible every significant advance in the nation's health services. The contemporary problems are certainly more complicated than those of the past, but they are no more difficult to solveif there is a will to solve them in the public interest.

Future progress in comprehensive health care, in education of the health professions, and in environmental health will depend in large measure on clear understanding by public and private groups of their respective responsibilities. Health needs in a nation of high material prosperity sometimes have a "low visibility" in comparison with other more obvious demands. Health needs are continuous. In a growing population they cannot be met by single actions expected to fill the bill for a generation.

In the United States, governmental agencies and institutions derive responsibilities and funds from the representatives of the people in Federal and State legislatures. Over the past quarter of a century, our national policy for community health facilities and services has been to provide Federal grants to the States, accompanied in some instances by other forms of assistance. The intent of the Congress has been to provide proportionally larger financial aid to the jurisdictions with low per capita income. This policy has been pursued consis- 
tently in Federal-State programs operated by the Public Health Service, the Social Security Administration, and the Office of Vocational Rehabilitation.

The pattern of Public Health Service grants for health research, training, and research facilities construction has been different. Here the aim has been to build up the nation's scientific potential through support of institutions and individual scientists. The same pattern has been applied in our programs for the advanced training of public health specialists and nurses.

In both these programs, research and training institutions in all parts of the country have benefited, whether operated under public or private auspices.

A second goal of these programs, aided by the Hill-Burton program, is to strengthen the nation's medical centers. These are at present the source of medical leadership in teaching, research, and clinical service-and the hope of the future.

State and local governments traditionally have borne the major burden for public health services. In the past decade, the proportional contribution of the Federal Government in those fields has declined, while that of State and local governments has increased sharply. This increase has occurred even in States with relatively meager economic resources.

State and local governments are also being called upon to play a larger role in types of health activity new to most of them. I refer particularly to research, education of the health professions, construction of community facilities, and administration of medical care programs covering larger segments of the population than previously came within their purview. The prominent role that private institutions have played in these areas will not, and must not, diminish. On the contrary, their role must increase. We cannot sustain progress in national health without substantial expansion of support from all sources. The stress of competition with other large national demands already has had an adverse impact on the nation's health institutions and agencies.

As a medical administrator, I know that highquality research, teaching, and service in my field cannot be performed without adequate support for personnel, facilities, and administration. In health fields, nothing less than high quality will suffice, for these activities touch people-in the most poignant experiences of their lives.

If expenditures for health lag too far behind increasing costs and increasing demands, the quality of health activities will deteriorate in the long run. If pressing demands for other civic needs are allowed to crowd out health needs, the effect on the economy of a State or of a nation can only be disastrous. In practical terms, achievements in other fields depend ultimately on a healthy, productive population. Development of health resources must keep pace with action in other areas of civic effort.

My contacts with other medical administrators in private and public organizations lead me to believe that the crowding out of health needs is occurring in many States. In others, there is a "slowing up" of support for new activities launched with enthusiasm only a few years ago.

The nation's medical centers, hospitals, and health departments cannot carry out the missions for which they were created without solid, sustained support. Nor can governments and private organizations afford the wastefulness of inadequate health resources.

These challenges confront the entire nation. We need to move forward now in a concerted effort to increase national health resources. Buttressed by an expanding research effort in all fields, our facilities, personnel, and organizations should be able to provide for the American people all the comprehensive health care and all the protection against environmental hazards that science affords.

But the nation's leaders at all levels of government must pick up the challenge wherever public responsibility is a factor in meeting the health needs of the nation. The health professions can identify these needs. They can point out the great opportunities for health progress. They can deliver the service. They can suggest ways to improve efficiency. But they cannot provide the means to accomplish them. Let it not be said that the world's richest nation in all history failed to meet the people's health needs. 


\section{Legal Note... Air Pollution-Abatement Orders}

Order which directed defendant to cease to "cause, suffer, allow, or permit open burning of refuse" held too vague to be enforceable when defendant did not cause fires in his open refuse dump. Department of Health v. Rosselle (N.J. Supreme Court 1961) 169 A. $2 d 153$.

The defendant appealed from a court order obtained by the New Jersey State Department of Health which held the defendant in civil contempt for failure to comply with a judgment of a lower court requiring the defendant to "cease violating the New Jersey Air Pollution Control Code as promulgated by the Air Pollution Control Commission" on premises operated as a refuse dump. The code provided that "No person shall cause, suffer, allow, or permit open burning of refuse ... Under the New Jersey Air Pollution Control Act the health department enforces the Air Pollution Control Code (N.J.S.A. 26:2C-9).

The charge revolved about the outbreak of fires in the defendant's dump, the origin of which was unknown. The health department conceded that the defendant had not started the fires and could not account for their origin.

On the merits of the case, the court held that enforcement of an injunctive order, such as at issue here, would not be denied merely because the violation was not willful. It held, however, that the order was too vague to sustain a finding that the defendant had violated it.

The court noted that, under the statute, upon a finding after a hearing that a violation of the Air Pollution Control Code existed, the health department was authorized to direct the taking of "such measures as may be necessary to prevent the same" (N.J.S.A. 26:2C-18). Thus, the court said, the statute directs the department to determine "in plain terms" what shall be done.

Since it was admitted that the defendant had not caused the fires, the violation of the code must rest on the charge that he did in fact "suffer, allow, or permit" the fires to occur. The only testimony offered, however, was proof of the fires and there was no evidence concerning measures the defendant should have taken, beyond what was done, to prevent or fight the fires.

The court noted that in the hearing held by the control commission prior to the adoption of the code it was pointed out that fires in open refuse dumps are frequently caused by the dumping of hot ashes, by spontaneous combustion, or by strangers to the operation. Sanitary landfills and incineration do not create the risk of such fires. The commission, however, chose to permit the continuance of open dumping in which the outbreak of fires was likely. (On June 30, 1960, the sanitary landfill method became mandatory for all dumps throughout the State.)

Under these circumstances the court held that the defendant was entitled to know in advance the specific measures which the department would deem sufficient to comply with the statute. The court pointed out that so long as the fires continued to break out, the defendant was required to risk the hazard of prosecution no matter what he did, and declared: "Any liability for the statutory penalty should not depend upon a defendant's ability to guess what will be found to be a sufficient provision to prevent fires or to extinguish them." The measures, said the court, "whatever they are, should have been specified in the departmental order" as contemplated by the statute.

The court criticized the order further, saying: "Nor, in terms of future compliance, can a restraint of such lazy generality be a truly effective remedy in the public interest. As the litigation demonstrates, it merely delays a solution by inviting controversies over what was meant and the sufficiency of what was done. Plaintiff increases its own workload when it resorts to generalities since sooner or later they must be made concrete. Plaintiff should use its ample power to deal with the problem with decisive clarity."

The court accordingly denied the health department's motion to punish the defendant, and left it to reinstitute its administrative procedures to abate the air pollution.

Comment. The court's holding emphasizes the administrative responsibility to decide clearly what the defendant is to be required to do, and to spell out the required measures in appropriate orders.

-Sidney Edelman, assistant chief, Public Health Division, Office of General Counsel, Department of Health, Education, and Welfare. 